\title{
Coordination of PSSs and SVC Damping Controller to Improve Probabilistic Small-Signal Stability of Power System With Wind Farm Integration
}

\author{
X. Y. Bian, Member, IEEE, Yan Geng, Kwok L. Lo, Yang Fu, and Q. B. Zhou
}

\begin{abstract}
A modified fruit fly optimization algorithm (MFOA) combined with a probabilistic approach are proposed in this paper to coordinate and optimize the parameters of power system stabilizers (PSSs) and static VAR compensator (SVC) damping controller for improving the probabilistic small-signal stability of power systems with large-scale wind generation, taking into consideration the stochastic uncertainty of system operating conditions. It is generally accepted that there is a threat to the stability of power system with penetration of wind farm. In addition, the stochastic fluctuations of wind generation make PSSs tuning more difficult. In this paper, PSSs and SVC damping controller are employed for suppressing local and inter-area low frequency oscillation. In order to eliminate the adverse effect between PSSs and SVC damping controller, the MFOA based on the probabilistic eigenvalue is applied to coordinate and optimize their parameters. The effectiveness of the proposed approach is verified on two test systems.
\end{abstract}

Index Terms-Modified fruit fly optimization algorithm (MFOA), power system stabilizer (PSS), probabilistic small-signal stability, static VAR compensator (SVC).

\section{INTRODUCTION}

I $\mathrm{N}$ recent years, the installation of renewable wind energy has expanded rapidly. Many large-scale wind farms are integrated to power grids through $110-\mathrm{kV}$ or $220-\mathrm{kV}$ transmission lines, which bring great and direct influence on the stability of main power networks. Impacts of large-scale wind power penetration on the power system stability have received much attention [1]-[3]. The random fluctuations of wind power output increase the uncertainty of system power balance [4], which will result in adverse effects on the system dynamic

Manuscript received January 30, 2015; revised June 04, 2015; accepted July 13, 2015. This work was supported in part by the National Natural Science Foundation of China under grant 51007054, in part by Shanghai Science and Technology Innovation Project under grant 14DZ1200905, and in part by Shanghai Engineering Research Center of Green Energy Grid-Connected Technology under grant 13DZ2251900. Paper no. TPWRS-00128-2015. (Corresponding author: Yan Geng.)

X. Y. Bian, Y. Geng, and Y. Fu are with Electric Power College, Shanghai University of Electric Power, Shanghai, China (e-mail: kuliz@163.com; gfx19891025@163.com; mfudong@126.com).

K. L. Lo is with the Department of Electronic \& Electrical Engineering, University of Strathclyde, Glasgow, Scotland, U.K. (e-mail: k.lo@strath.ac.uk).

Q. B. Zhou is with Shanghai Lightning Protection Center, Shanghai, China (e-mail: 35769803@qq.com).

Color versions of one or more of the figures in this paper are available online at http://ieeexplore.ieee.org.

Digital Object Identifier 10.1109/TPWRS.2015.2458980 stability, especially the small-signal stability. It is important to analyze the power system small-signal stability with probabilistic methods [1], [5] and consider the effects of uncertainty of wind farm output and stochastic changes of loads. References [1], [6], and [7] represent some investigations along that line. Their work verifies the effectiveness of the probabilistic approach and illustrates that the integration of large-scale wind farms could cause the power system probabilistic small-signal instability that could be difficult to overcome. However, [1], [6], and [7] do not propose effective measures to improve the probabilistic small-signal stability, especially for damping the inter-area mode with wind power variations.

Application of power system stabilizers (PSSs) is normally a first measure to enhance the system small-signal stability. Large-scale wind farm integration can induce a higher probability of system instability when compared to one without wind generation [6], [7]. Uncertain fluctuations of wind generator output also make PSSs tuning more difficult [8]. In some cases, when the use of PSSs cannot provide sufficient damping for inter-area power swing $(0.1-0.7 \mathrm{~Hz}), \mathrm{SVC}$ damping controller is an alternative effective solution. The primary application of SVC in a power system with integration of wind farm is to maintain the busbar voltage and provide reactive power support [9], [10]. With a damping controller installed, SVC can provide extra damping [11], [12]. SVC and PSSs are all fast acting power controller devices. There is a potential possibility that these devices may interact adversely with each other and may not produce the expected performance. To improve their overall combined performance, it is necessary to coordinate and optimize the PSSs and SVC damping controller parameters. A few researches are made along that line [13]-[15]. However, [13] and [14] are based on linearized power system around certain specified operating points (i.e., deterministic). With a linearized model, controller settings which are able to stabilize the system around certain specified operating points may not perform satisfactorily at other points. In [15], the probabilistic eigenvalue sensitivity analyses are carried out for the design of PSSs and SVC damping controller for power system small-signal stability enhancement, without considering the stochastic fluctuations of wind power output.

In the design of controller parameters, one single parameter usually influences more than one oscillation mode. The genetic algorithms (GAs) [16], [17] and the particle swarm optimization (PSO) [18] have been widely used as optimization tools. However, the GA requires long computational time and also suffers 
from premature convergence. The PSO may easily fall into and then be trapped at a local optimal point. The fruit fly optimization algorithm (FOA) [19], [20] has a high searching precision. It is simple and it has only a few parameters to be set but they can be easily adjusted. It also enjoys a high global search capacity. However, the FOA is not suitable for solving problems whose independent variables can have negative values. Thus a modified fruit fly optimization algorithm (MFOA) is proposed to avoid the limitation that variables of the fitness function are restricted to be in the zone of $(0,+\infty)$.

In this paper, a probabilistic method based on numerical analysis is proposed to analyze statistical attributes of the smallsignal stability of the power system with grid-connected wind power source. The analysis takes into consideration multi-operating conditions including the stochastic variations of wind farm output, the random fluctuations of synchronous generator output, loads and nodal voltages variations. Plug-in modeling technology (PMT) [21] is adopted to construct the state matrix of the whole system. The SVC supplemented with damping controller and PSSs on synchronous generators are applied to increase the probability of stability. For coordinating and optimizing parameters of PSSs and SVC damping controller, the MFOA [22]-[24] is developed and applied.

The main structure of this paper is as follows. Section I introduces the research motivation and objective of this paper. In Section II, the models of PSS and SVC with damping controller are presented. The probabilistic eigenvalue expression and probability distribution of eigenvalues are discussed in Section III. The proposed optimization algorithm combined with probabilistic method to solve the coordination problem among PSSs and SVC damping controller by MFOA are formulated in Section IV. The negative average value of the extended expectation of the damping constant of all oscillation modes is taken as the objective function subjected to multiple constraints. To validate the efficiency and feasibility of the proposed method, two case studies are presented. The first one is based on a five-machine two-area power system with a grid-connected wind farm to illustrate the design principle of the proposed approach, presented in Section V. The second one is a larger and more complex power system with eight machines, three areas and with a grid-connected wind farm to give a more strenuous test to the proposed approach, illustrated in Section VI. Some conclusions are drawn in Section VII.

\section{PSS AND SVC DAMPING CONTROLLER}

The MFOA combined with the probabilistic method proposed in this paper is used to devise damping techniques for PSSs and SVC damping controller to improve the probabilistic small-signal stability of the power system with wind farm integration. This section gives the meaning of parameters of the PSS and SVC damping controller, respectively.

\section{A. PSS}

The basic function of a PSS is to extend stability limits by modulating generator excitation to provide the damping to the oscillations. The linearized module of PSS is shown in Fig. 1, where $K_{\mathrm{PSS}}$ is the PSS gain, $p$ represents the differential operator, $T_{w}$ and $T_{1} / T_{2}$ are the wash-out and the lead/lag time

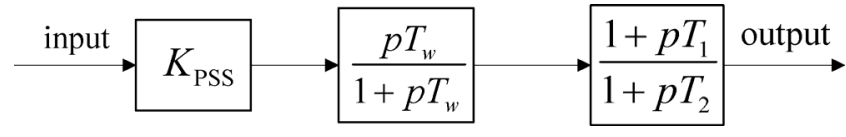

Fig. 1. Module of the PSS.

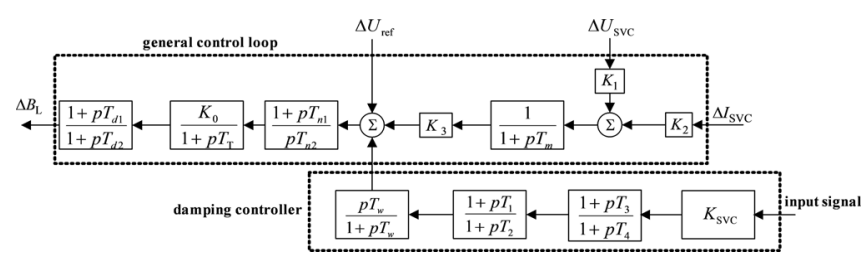

Fig. 2. Control model of the SVC.

constants, respectively. The signal washout block serves as a high-pass filter. The gain $K_{\text {PSS }}$ determines the damping introduced by the PSS and the lead/lag block is used to achieve the desired phase compensation [25].

\section{B. Module of SVC With Damping Controller}

The primary application of SVC is to maintain the busbar voltage at a predefined value. An SVC equipped with a voltage regulator may provide synchronizing torque but negligible damping torque [26]. A damping controller is necessary when extra damping is needed.

A typical SVC configuration consists of a thyristor controlled inductor and a fixed capacitor and is normally connected to a busbar through a step-down transformer as shown in [15] and [27]. An SVC thyristor controller block is shown in Fig. 2 where $\Delta U_{S V C}$ and $\Delta I_{S V C}$ are the magnitudes of voltage and current at the SVC terminal and $\Delta B_{\mathrm{L}}$ is the controller output. In addition, a damping controller is shown in Fig. 2, where $K_{S V C}$ is the SVC damping controller gain, $T_{w}$ is the wash-out time constant, $T_{1} / T_{2}$ and $T_{3} / T_{4}$ are the lead/lag time constants.

\section{Probabilistic Eigenvalue AND Its Distribution}

One of the contributions of this paper is to consider a wide range of power system operating conditions and this information is incorporated by modeling loads, output of wind farm and synchronous generators as nodal injections whose expectations and variances are known. All nodal voltages, nodal injections, and eigenvalues are now regarded as random variables. The objective of this section is to determine the expectation and probabilistic distribution of the system eigenvalues.

\section{A. Probabilistic Eigenvalue Expression}

A particular eigenvalue $\lambda_{k}$ of the coefficient matrix of the linearized system's dynamic equations or state matrix $A$ [28] can be analytically expressed as the nonlinear function of nodal voltages vector

$$
\lambda_{k}=g_{k}(U)
$$

where nodal voltages are defined in rectangular coordinates and the voltage vector $U$ contains $2 N$ components as $U$ $=\left[u_{1}, u_{2}, \ldots, u_{2 N}\right]^{\mathrm{T}}$ in a power system of $N$ nodes.

The expectation of eigenvalue $\lambda_{k}$ is expressed as in (2): 


$$
\bar{\lambda}_{k}=g_{k}(\bar{U})
$$

where the expectation operator is expressed as $\overline{(.)}$.

The direct use of the function in (2) is complicated, an alternative method is used to calculate the expectation of $\lambda_{k}$.

Equation (1) can be expanded in Taylor series at the vicinity of the expected value of voltage, and the approximation with the second-order and higher order terms neglected is

$$
\begin{aligned}
\lambda_{k} & =g_{k}(\bar{U})+\sum_{i=1}^{2 N}\left(\left.\frac{\partial g_{k}}{\partial U_{i}}\right|_{U=\bar{U}} \Delta U_{i}\right) \\
& =g_{k}(\bar{U})+\sum_{i=1}^{2 N}\left(J_{\lambda_{k, i}} \Delta U_{i}\right)
\end{aligned}
$$

where

$$
J_{\lambda_{k, i}}=\left.\frac{\partial g_{k}}{\partial U_{i}}\right|_{U=\bar{U}}=\left.\frac{\partial \lambda_{k}}{\partial U_{i}}\right|_{U=\bar{U}}, \quad i=1,2, \ldots, 2 N
$$

where $U_{i}$ is the real part or imaginary part of node- $i$ voltage, numerical value of each element in (4) is derived using (5) [29]:

$$
J_{\lambda_{k, i}}=\frac{l_{k}^{\mathrm{T}} \frac{\partial A}{\partial U_{i}} r_{k}}{l_{k}^{\mathrm{T}} r_{k}}
$$

where $r_{k}$ and $l_{k}$ denote the right and left eigenvector corresponding to $\lambda_{k}$, respectively. The derivative of the state matrix $A$ for the voltage vector can be obtained using the PMT [28]. Each numerical value calculated according to (5) is inserted into (3) to compute the expression of $g_{k}(\bar{U})$, i.e., the expectation of $\lambda_{k}$.

\section{B. Probabilistic Distribution of Eigenvalue}

Considering the stochastic wind power output and load, the system eigenvalues can have an arbitrary distribution and can be obtained through the probability theory analysis of a hybrid algorithm using central moments and cumulants combined with the Gram-Charlier series [30]. The higher the order of cumulant in a Gram-Charlier series, the weaker will be its effect on the entire distribution. To reduce the amount of computation, only the first five order cumulants are used with adequate computing accuracy [31]. The probability density function (PDF) and cumulative distribution function of $\lambda_{k}$ can be expressed in (6) and (7), respectively [8]:

$$
\begin{aligned}
f\left(\lambda_{k}\right)= & N(\tilde{x})\left[1+\frac{\gamma_{3}\left(\lambda_{k}\right)}{6 \sigma_{k}^{3}}\left(\tilde{x}^{3}-3 \tilde{x}\right)\right. \\
& +\frac{\gamma_{4}\left(\lambda_{k}\right)}{24 \sigma_{k}^{4}}\left(\tilde{x}^{4}-6 \tilde{x}^{2}+3\right) \\
& \left.+\frac{\gamma_{5}\left(\lambda_{k}\right)}{120 \sigma_{k}^{5}}\left(\tilde{x}^{5}-10 \tilde{x}^{3}+15 \tilde{x}\right)\right] \\
P\left\{\lambda_{k}<x_{c}\right\}= & \int_{-\infty}^{\tilde{x}_{c}} N(x) d x \\
& -N\left(\tilde{x}_{c}\right)\left[\frac{\gamma_{3}\left(\lambda_{k}\right)}{6 \sigma_{k}^{3}}\left(\tilde{x}_{c}^{2}-1\right)\right. \\
& +\frac{\gamma_{4}\left(\lambda_{k}\right)}{24 \sigma_{k}^{4}}\left(\tilde{x}_{c}^{3}-3 \tilde{x}_{c}\right)
\end{aligned}
$$

$$
\left.+\frac{\gamma_{5}\left(\lambda_{k}\right)}{120 \sigma_{k}^{5}}\left(\tilde{x}_{c}^{4}-6 \tilde{x}_{c}^{2}+3\right)\right]
$$

where $f\left(\lambda_{k}\right)$ is PDF of the eigenvalue $\lambda_{k}, N(x)$ is PDF for the standard normal distribution, $\gamma_{j}\left(\lambda_{k}\right)(j=3,4,5)$ is a $j$-order cumulant [32], $\sigma_{k}$ is the standard deviation of the eigenvalue, $\tilde{x}$ is the standardized $\lambda_{k}$ determined by

$$
\begin{gathered}
\tilde{x}=\frac{\lambda_{k}-\overline{\lambda_{k}}}{\sigma_{k}} \\
\tilde{x}_{c}=\frac{x_{c}-\overline{\lambda_{k}}}{\sigma_{k}} .
\end{gathered}
$$

\section{CoORdination AND Optimization AMONG PSSS AND SVC CONTROLLER BASED ON MFOA}

The coordination problem is concocted into an optimization problem of an eigenvalue-based objective function. The expectation of an eigenvalue $\lambda_{k}=\alpha_{k}+j \omega_{k}$ is

$$
\bar{\lambda}_{k}=\bar{\alpha}_{k}+\mathrm{j} \bar{\omega}_{k}
$$

where $\bar{\alpha}_{k}$ is the expectation of the damping constant $\alpha_{k}$.

For optimization purposes, the extended expectation of the damping constant is introduced, and it can be represented as a function of parameters of PSSs and SVC damping controllers:

$$
\begin{aligned}
\alpha_{k}^{*}=\frac{\bar{\alpha}_{k}}{\sigma_{k}}=f\left(K_{\mathrm{PSS} m}, T_{1 \mathrm{PSS} m}, T_{2 \mathrm{PSS} m},\right. \\
\left.K_{S V C h}, T_{1 S V C h}, T_{2 S V C h}, T_{3 S V C h}, T_{4 S V C h}\right)
\end{aligned}
$$

where $\alpha_{k}^{*}$ represents the extended expectation of the damping constant, $m$ and $h$ represent the total number of PSSs and SVC damping controllers, respectively, the meaning of the parameters $K_{\mathrm{PSS}}, K_{S V C}, T_{1} / T_{2}$, and $T_{3} / T_{4}$ are explained in Section II-A and B, respectively.

Then the objective function of the optimization problem is represented as

$$
\max g=-\frac{\left(\sum_{k=1}^{n} \alpha_{k}^{*}\right)}{n}
$$

subject to

$$
\begin{aligned}
\bar{\alpha}_{k} & <0, \quad k=1,2, \ldots, n \\
0 & <K_{\mathrm{PSS} m} \leq 10 \\
-3.5 & <K_{S V C h}<0 \\
0 & <T_{1 b}, T_{2 b}<1, b=m+h \\
0 & <T_{3 h}, T_{4 h}<1 \\
\bar{\xi}_{k} & \geq 0.05
\end{aligned}
$$

where $n$ is the total number of oscillation modes, $\bar{\xi}_{k}$ [28] is the expectation of damping ratio of $\lambda_{k}$. For the washout stage and viewing from the angle of the washout function, the precise value of the associated time constant $T_{w}$ is not critical. The main consideration is that the value should be sufficiently small so that it has insignificant effects on the stabilizing signals at the frequencies of interest. For this reason, $T_{w}$ is considered to be a known parameter and $T_{w}=10 \mathrm{~s}$ for PSSs and SVC damping controllers. 
The MFOA [23], [24] is used for coordinating and optimizing parameters of PSSs and SVC damping controller. It can avoid the problems of limitation that variables of the fitness function are in the zone of $(0,+\infty)$ in FOA [19], [20]. It is much simpler and more robust when compared with other optimization methods, e.g., GA, PSO and ant colony optimization algorithm. Its steps are as follows:

Step 1) Fruit fly swarm location range is initialized randomly within $[0,100]$ :

$$
\begin{aligned}
& X \_ \text {axis }=100 * \operatorname{rand}(1,2) \\
& Y_{\_} \text {axis }=100 * \operatorname{rand}(1,2) \\
& Z_{\text {_axis }}=100 * \operatorname{rand}(1,2)
\end{aligned}
$$

where rand () is the random numbers between 0 and 1.

Step 2) Set the random direction and distance for the search of food using osphresis by an individual fruit fly, the random fly direction and distance zone of iterative fruit fly food searching is $[-5.5,5.5]$ :

$$
\begin{aligned}
X_{i} & =X \_a x i s+11 * \operatorname{rand}(1,2)-(5.5,5.5) \\
Y_{i} & =Y \_a x i s+11 * \operatorname{rand}(1,2)-(5.5,5.5) \\
Z_{i} & =Z_{\_} \text {axis }+11 * \operatorname{rand}(1,2)-(5.5,5.5) .
\end{aligned}
$$

Step 3) Since the food location is not known, the distance to the origin is an estimate (Dist), then the smell concentration judgment value $(S)$ is calculated:

$$
\begin{aligned}
\text { Dist }_{i} & =\sqrt{X_{i}^{2}+Y_{i}^{2}+Z_{i}^{2}} \\
S_{i} & =\frac{1}{\text { Dist }_{i}}+\Delta
\end{aligned}
$$

where

$$
\Delta=\operatorname{Dist}_{i} *(0.5-\delta), 0 \leq \delta \leq 1 .
$$

Step 4) Substitute $S$ in (17) into smell concentration judgment function (or called fitness function), so as to find the smell concentration $\left(\mathrm{Smell}_{i}\right)$ of the individual location of the fruit fly:

$$
\text { Smell }_{i}=\text { Function }\left(S_{i}\right)
$$

where $S m e l l_{i}$ is the objective function, $S_{i}$ is the independent variable of the objective function, i.e., the $i$ th tuned parameter of PSSs and SVC damping controllers.

Step 5) Determine the fruit fly with the maximal smell concentration (finding the maximal value) among the fruit fly swarm:

$[$ bestSmell, bestIndex $]=\max ($ Smell $)$.

Step 6) Keep the best smell concentration value and $x, y$ coordinate, and from this moment onwards, the fruit fly swarm will use vision to fly towards that location:

$$
\begin{aligned}
\text { Smellbest } & =\text { bestSmell } \\
X \_a x i s & =X(\text { bestIndex })
\end{aligned}
$$

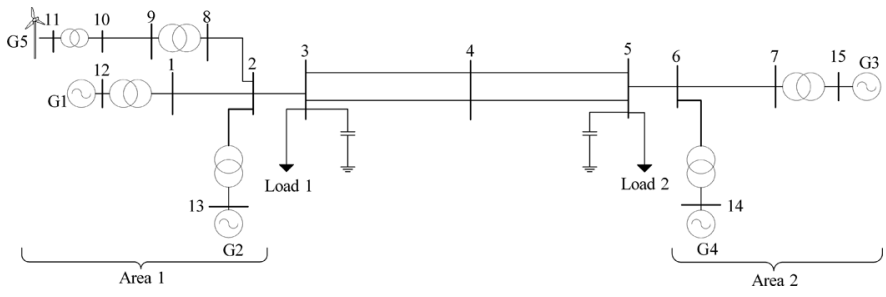

Fig. 3. Two-area system with wind farm integration.

$$
\begin{aligned}
& Y \_a x i s=Y(\text { bestIndex }) \\
& Z_{\text {_axis }}=Z(\text { bestIndex })
\end{aligned}
$$

Step 7) Enter iterative optimization to repeat the implementation of steps $2-5$, then evaluate whether the smell concentration is superior to the previous iterative smell concentration, if so, implement the step 6 .

According to the above iterative steps, parameters which need to set are the fruit fly population size, the initial location, the random fly direction and distance zone of iterative fruit fly food searching, and the iterative number.

\section{CASE Study I: Five-Machine Two-Area System}

To illustrate the principle of the proposed probabilistic eigenvalue analysis method and the coordination and optimization approach, a case study is undertaken on a five-machine two-area system. Simulation results of the performance of the test system are compared under four different scenarios including: in Section V-B the test system with PSSs only; in Section V-C the test system with SVC only; in Section V-D the test system with uncoordinated PSSs and SVC damping controller; and in Section V-E the test system with coordinated PSSs and SVC damping controller.

\section{A. Test System}

The five-machine two-area system in Fig. 3 is modified from a typical two-area system of [33], which is widely used for studies of power system small-signal stability. This system demonstrates both local and inter-area oscillation modes. The network and synchronous generator data can be obtained in [33]. All synchronous generators are represented using 6-order models and are extended to include exciter and PSS models. G1 and G2 are equipped with fast exciters and G3 and G4 with slow exciters. G5 represents a wind farm with a capacity of $120 \mathrm{MW}$ or 80 DFIGs with $1.5 \mathrm{MW}$ each. Details of the test system and DFIG model and parameters are listed in [8] and [34]-[36]. In this study, the cumulative load duration curves shown in Fig. 4, the nodal power of synchronous generators and the wind farm output shown in Fig. 5, and the balancing machine (G3) voltage and the wind farm voltage shown in Fig. 6 are employed.

\section{B. Probabilistic Eigenvalue and Participation Factor Analysis With PSSs Only}

The proposed probabilistic method in Section III is applied to the test system. Firstly, the accuracy of the probabilistic eigenvalue calculation is evaluated. Results of a selected mode (Mode 1) obtained by the proposed approach are compared with that 


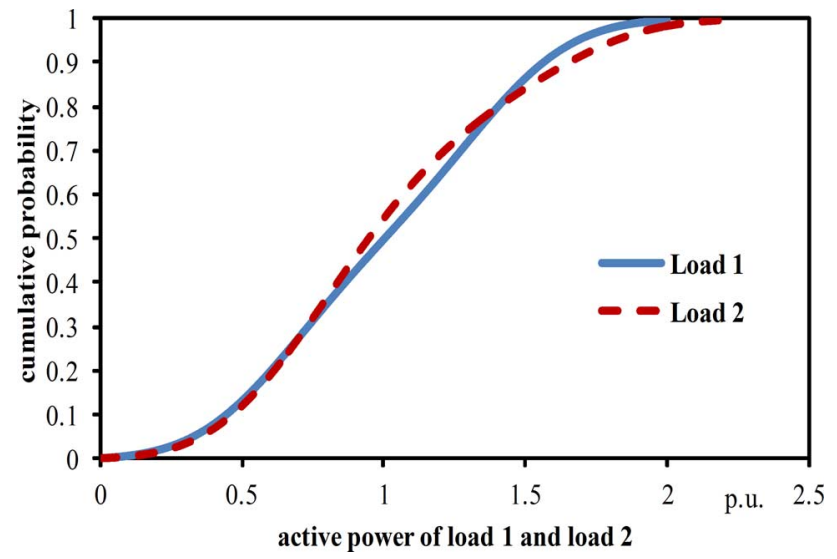

Fig. 4. Cumulative probability of the active power of load 1 and load 2.

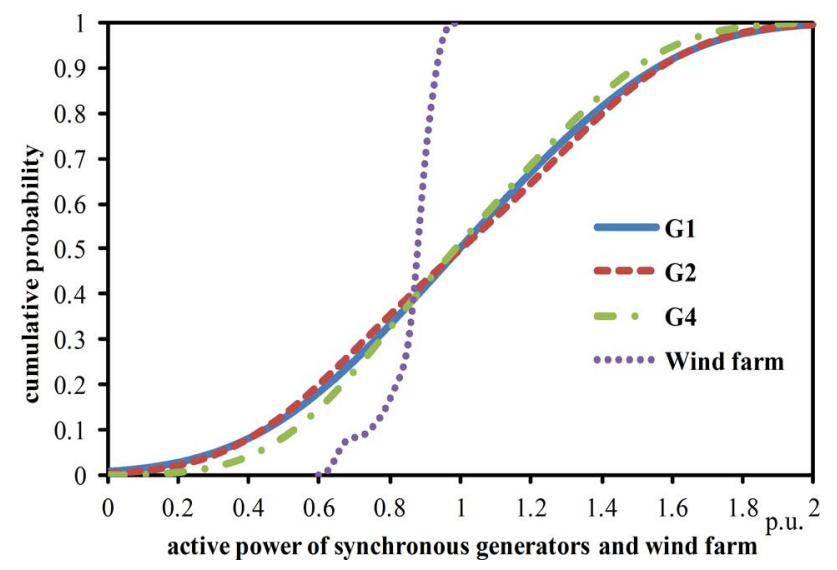

Fig. 5. Cumulative probability of the active power of synchronous generators and wind farm.

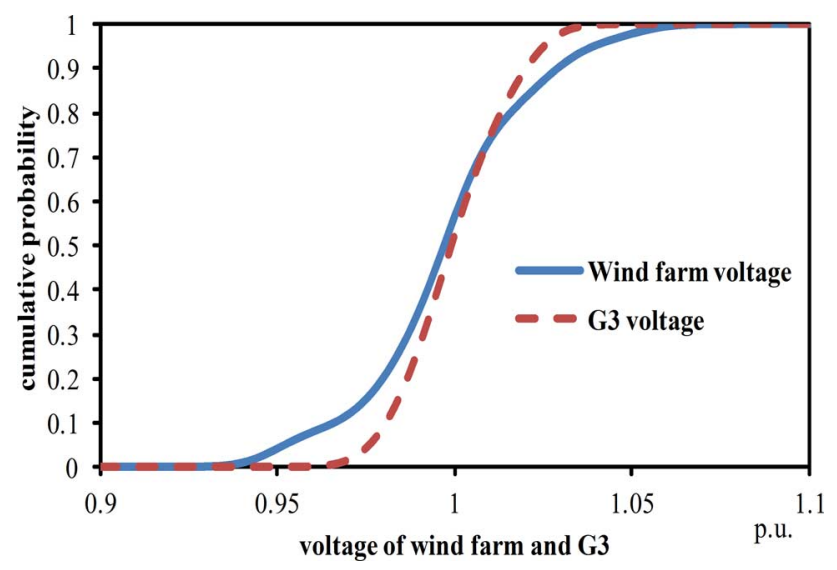

Fig. 6. Cumulative probability of the voltage of wind farm and G3.

computed by Monte Carlo simulations (4800 times), as shown in Fig. 7. The comparison indicates that the proposed probabilistic method in handling the stochastic uncertainty of system operating conditions can achieve sufficient accuracy to approximate the probabilistic density curve that is supported by the result of the Monte Carlo simulations.

For the system with wind farm connected, by analyzing the participation factor and mode shapes, as shown in Table I and

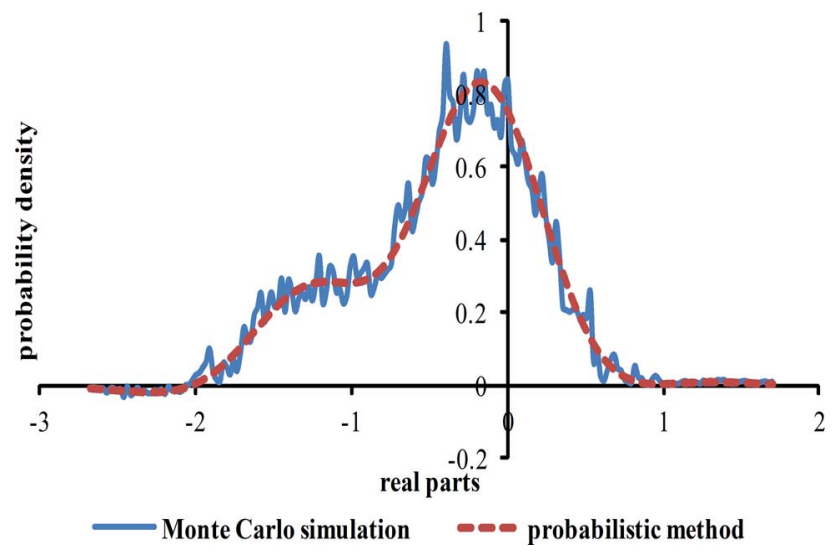

Fig. 7. Real part PDF of Mode 1 obtained by the Monte Carlo method and the probabilistic method.
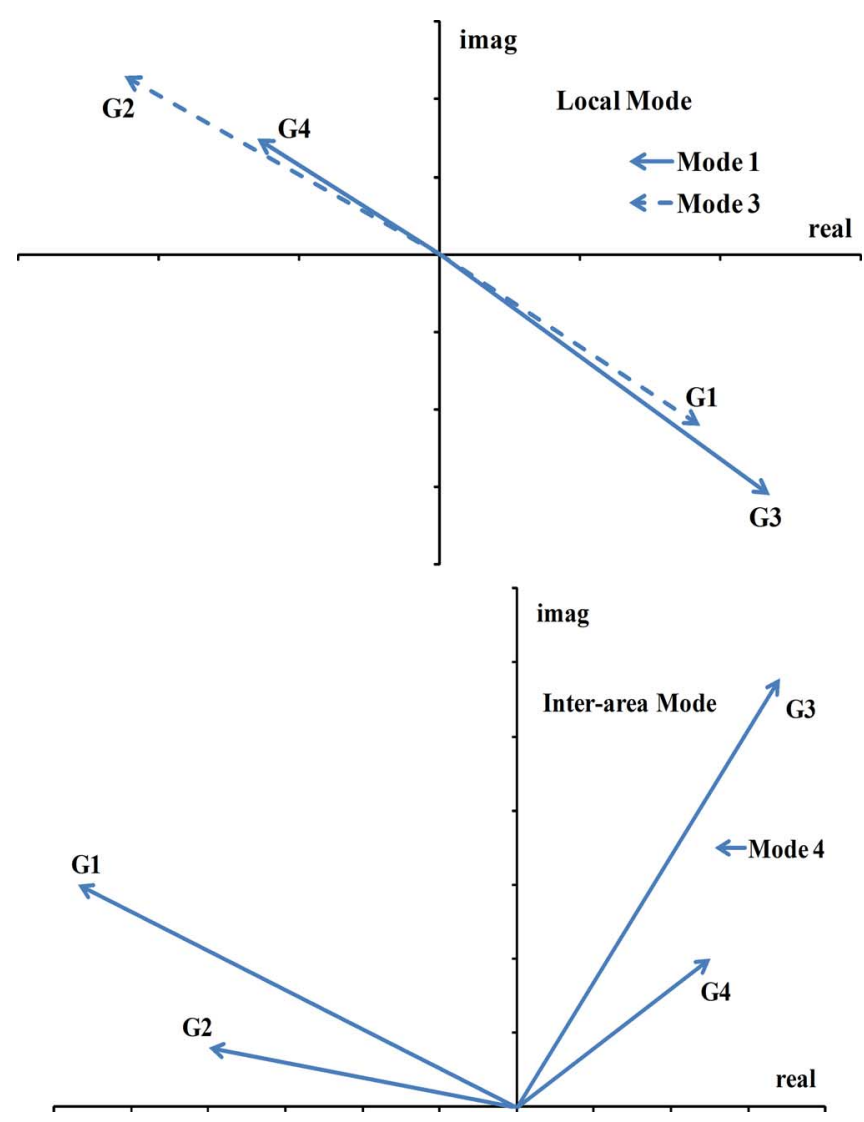

Fig. 8. Mode shapes of rotor angle modes.

Fig. 8, Mode 1 and Mode 3 belong to local oscillation, Mode 4 is inter-area oscillation. Although the frequency of Mode 2 is within the range of inter-area oscillation $(0.2 \sim 0.7 \mathrm{~Hz})$, Mode 2 is caused mainly by the wind farm G5.

With PSSs installed in four synchronous generators and their initial parameters (Table II), the probabilistic eigenvalues are obtained. The PSSs' gains are determined by using the probabilistic sensitivity index (PSI) corresponding to the residue index [29] and the initial time settings are estimated according to the phase shift of the excitation in the system. Table III gives information about the probabilistic distribution of these four 
TABLE I

PARTICIPATION FACTOR OF CONCERNED MODES

\begin{tabular}{cccccc}
\hline Mode & G1 & G2 & G3 & G4 & G5 \\
\hline 1 & 0.002 & 0 & 0.363 & 0.231 & 0 \\
2 & 0 & 0.004 & 0.003 & 0.001 & 0.512 \\
3 & 0.250 & 0.391 & 0 & 0 & 0.002 \\
4 & 0.342 & 0.164 & 0.221 & 0.133 & 0.001 \\
\hline
\end{tabular}

TABLE II

PARAMETERS OF PSSS IN SYNCHRONOUS GENERATORS

\begin{tabular}{cccccc}
\hline & & PSS1 & PSS2 & PSS3 & PSS4 \\
\hline \multirow{2}{*}{ Initial } & $T_{1}$ & $0.837 \mathrm{~s}$ & $0.285 \mathrm{~s}$ & $0.880 \mathrm{~s}$ & $0.392 \mathrm{~s}$ \\
parameters & $T_{2}$ & $0.176 \mathrm{~s}$ & $0.797 \mathrm{~s}$ & $0.366 \mathrm{~s}$ & $0.780 \mathrm{~s}$ \\
& $K$ & 1.5 & 10 & 5 & 9 \\
\hline \multirow{2}{*}{ Optimized } & $T_{1}$ & $0.795 \mathrm{~s}$ & $0.306 \mathrm{~s}$ & $0.925 \mathrm{~s}$ & $0.361 \mathrm{~s}$ \\
parameters & $T_{2}$ & $0.153 \mathrm{~s}$ & $0.614 \mathrm{~s}$ & $0.407 \mathrm{~s}$ & $0.757 \mathrm{~s}$ \\
& $K$ & 2.7 & 9.6 & 4 & 8.5 \\
\hline
\end{tabular}

TABLE III

Probability OF OSCILLATION MODES With PSSS ONLY

\begin{tabular}{ccccc}
\hline & $\begin{array}{c}\text { Eigenvalues } \\
\bar{\alpha} \pm \mathrm{j} \bar{\omega}\end{array}$ & $\begin{array}{c}\text { Damping } \\
\text { ratio } \bar{\xi}\end{array}$ & $\begin{array}{c}\mathrm{P}\{\alpha<0\} \\
(\%)\end{array}$ & $\begin{array}{c}\mathrm{P}\{\xi>0.1\} \\
(\%)\end{array}$ \\
\hline $\begin{array}{c}\text { PSSs with } \\
\text { initial }\end{array}$ & $-0.7849 \pm \mathrm{j} 6.4001$ & 0.3692 & 62.97 & 61.74 \\
parameters & $-1.5386 \pm \mathrm{j} 2.8729$ & 0.3090 & 63.88 & 62.35 \\
& $-0.7716 \pm \mathrm{j} 3.0292 .5630$ & 0.2651 & 56.71 & 54.02 \\
& $-0.9604 \pm \mathrm{j} 6.3378$ & 0.0236 & 69.53 & 2.81 \\
\hline PSSs & $-1.8841 \pm \mathrm{j} 2.8621$ & 0.4392 & 86.92 & 76.58 \\
optimized & $-1.7159 \pm \mathrm{j} 5.6041$ & 0.2765 & 84.13 & 81.04 \\
& $-0.8429 \pm \mathrm{j} 3.0597$ & 0.0811 & 79.37 & 24.29 \\
\hline
\end{tabular}

modes. It shows that the stability problem is likely to occur because these four modes have low probability to remain in the left half-plane, and are poorly damped.

The MFOA, described in Section IV, is implemented. The number of swarm used in the MFOA is set to 12; the number of fruit flies in each swarm is set to 20 ; the target value is 180 , and the number of iteration is set to 100 . Then the parameters of PSSs can be tuned, so does the root mean square error (RMSE) between the network output value and the target value is reduced.

After 100 times of iterative evolution, convergence is obtained in the 39th generation, and the corresponding RMSE is 0.0529. The values of optimized parameters of PSSs are shown in Table II.

The corresponding stability probability statistics of critical oscillation modes have increased significantly, as shown in Table III. From the table, it is clear that the optimized PSSs improve the damping performance of Mode 1,2, and 3. The stability probability of the inter-area Mode 4 is the lowest,
TABLE IV

CRITICAL OSCILLATION MODES With SVC CONTROLLER ONLY

\begin{tabular}{|c|c|c|c|c|}
\hline & $\begin{array}{l}\text { Eigenvalues } \\
\qquad \bar{\alpha} \pm \mathbf{j} \bar{\omega}\end{array}$ & $\begin{array}{l}\text { Damping } \\
\text { ratio } \bar{\xi}\end{array}$ & $\begin{array}{c}\mathrm{P}\{\alpha<0\} \\
(\%)\end{array}$ & $\begin{array}{c}\mathrm{P}\{\xi>0.1\} \\
(\%)\end{array}$ \\
\hline \multirow{4}{*}{$\begin{array}{l}\text { SVC with } \\
\text { initial } \\
\text { parameters }\end{array}$} & $-0.6915 \pm \mathrm{j} 6.3903$ & 0.3012 & 43.51 & 37.92 \\
\hline & $-1.8054 \pm \mathrm{j} 2.8736$ & 0.2698 & 50.32 & 40.83 \\
\hline & $-1.4026 \pm \mathrm{j} 5.5913$ & 0.2403 & 54.13 & 49.26 \\
\hline & $-0.8124 \pm \mathrm{j} 3.0048$ & 0.0786 & 74.09 & 20.17 \\
\hline \multirow{4}{*}{$\begin{array}{c}\text { SVC } \\
\text { optimized }\end{array}$} & $-0.6928 \pm \mathrm{j} 6.3891$ & 0.3014 & 43.71 & 37.92 \\
\hline & $-1.8054 \pm \mathrm{j} 2.8736$ & 0.2698 & 50.32 & 40.83 \\
\hline & $-1.4513 \pm \mathrm{j} 5.5827$ & 0.2513 & 54.51 & 49.27 \\
\hline & $-0.9647 \pm \mathrm{j} 3.0261$ & 0.2568 & 87.32 & 82.41 \\
\hline
\end{tabular}

with a probability $\mathrm{P}\{\alpha<0\}$ of $79.37 \%$ to remain in the left half-plane. The expectation of its damping ratio is 0.0811 and the probability of it more than 0.1 is $24.29 \%$. These make the PSSs tuning difficult, and the use of SVC damping controller is considered.

\section{Probabilistic Small-Signal Stability Analysis With SVC Damping Controller Only}

To improve the inter-area mode, one SVC is installed. Generally, the tie-line electrical midpoint is the lowest point of system voltage [37], and the placing of the SVC near or in the tie-line is beneficial to improve the voltage. Therefore, the SVC with a damping controller is installed at Bus 4, which not only can contribute voltage stability but it can also improve small-signal stability.

The Current amplitude in the transmission line between Bus 3 and Bus $4 I_{3-4}$ is employed as the input signal [38], [39] to the damping controller. Values of parameters used in the general control loop of the SVC are set as $X_{\mathrm{T}}=0.014, B_{\mathrm{C}}=1.0$, $B_{\mathrm{L}}=-1.02, K_{1}=28, K_{2}=-1.0, K_{3}=-1.5, T_{m}=0.5 s$, $T_{\mathrm{n} 1}=0.01 \mathrm{~s}, T_{\mathrm{n} 2}=0.13 \mathrm{~s}, K_{0}=0.8, T_{\mathrm{T}}=0.0015 \mathrm{~s}$, $T_{\mathrm{d} 1}=-0.0025 \mathrm{~s}$, and $T_{\mathrm{d} 2}=0.025 \mathrm{~s}$. The Initial gain of the SVC damping controller is chosen as $K_{S V C}=-0.1$ which is determined by the PSI corresponding to the residue index [15], and the initial time settings are chosen as $T_{1}=0.018 \mathrm{~s}$, $T_{2}=0.150 \mathrm{~s}, T_{3}=0.600 \mathrm{~s}$, and $T_{4}=0.500 \mathrm{~s}$ according to the phase-compensation method [12]. The statistical results of critical oscillation modes are shown in Table IV. Then the MFOA is implemented to optimize the parameters of the SVC damping controller. The number of swarm used in the MFOA is 5.

After 100 times of iterative evolution, convergence is obtained in the 26th generation, and the corresponding RMSE is 0.0587 . The optimized parameters of the SVC damping controller are listed in the following:

$$
\begin{aligned}
& T_{1}=0.315 \mathrm{~s}, T_{2}=0.729 \mathrm{~s} \\
& T_{3}=0.912 \mathrm{~s}, T_{4}=0.435 \mathrm{~s}, K_{S V C}=-1.2 .
\end{aligned}
$$

The corresponding stability probability statistics of critical oscillation modes are presented in Table IV. It is obvious that 
TABLE V

CRitical OsCillation Modes With UnCoOrdinated PSSS AND SVC CONTROLLER

\begin{tabular}{ccccc}
\hline Mode & $\begin{array}{c}\text { Eigenvalues } \\
\bar{\alpha} \pm \mathrm{j} \bar{\omega}\end{array}$ & $\begin{array}{c}\text { Damping } \\
\text { ratio } \bar{\xi}\end{array}$ & $\begin{array}{c}\mathrm{P}\{\alpha<0\} \\
(\%)\end{array}$ & $\begin{array}{c}\mathrm{P}\{\xi>0.1\} \\
(\%)\end{array}$ \\
\hline 1 & $-0.9564 \pm \mathrm{j} 6.3147$ & 0.4728 & 83.06 & 72.95 \\
2 & $-1.8715 \pm \mathrm{j} 2.8623$ & 0.4172 & 81.21 & 70.41 \\
3 & $-1.7423 \pm \mathrm{j} 5.6697$ & 0.2784 & 84.65 & 81.18 \\
4 & $-0.7821 \pm \mathrm{j} 3.1726$ & 0.0537 & 72.89 & 16.94 \\
5 & $1.0129 \pm \mathrm{j} 0.3025$ & -0.9264 & 3.57 & 0.00 \\
\hline
\end{tabular}

the optimized SVC damping controller effectively improves the inter-area mode (Mode 4).

\section{Probabilistic Small-Signal Stability Analysis With Uncoordinated PSSs and SVC Damping Controller}

To improve the local modes and inter-area mode, four PSSs and one SVC are installed to improve the probabilistic stability of the test system. The parameters of PSSs are the same as the optimized parameters in Table II of Section V-B. The parameters of the SVC controller are the same as the optimized parameters in (23) in Section V-C. But the parameters of PSSs and the SVC damping controller are not yet coordinated. The corresponding statistical results of critical oscillation modes are shown in Table V. Comparing Table V with Table IV, the damping ratio expectation of the inter-area mode (Mode 4) decreases to 0.0537 from 0.2568 , the stability probability decreases to $72.89 \%$ from $87.32 \%$. Furthermore, there is a new oscillation mode (Mode 5), and the expectation of its damping ratio is -0.9264 . All these non-ideal oscillation modes above are caused by the uncoordinated design of PSSs and SVC damping controller.

\section{E. Probabilistic Small-Signal Stability Improvement With Coordinated PSSs and SVC Damping Controller}

From the analysis of the three aforementioned scenarios, coordination among PSSs and SVC damping controller is desirable to improve the overall system damping. Therefore, the MFOA is implemented. The number of swarm used is 17.

Fig. 9 gives the convergent characteristics of the MFOA. It can be seen from the curve that convergent is obtained in the 43rd generation, and the corresponding RMSE is 0.0506 . The final values of optimized parameters of PSSs are shown in Table VI and the parameters of the SVC damping controller are listed in the following:

$$
\begin{aligned}
& T_{1}=0.417 \mathrm{~s}, T_{2}=0.964 \mathrm{~s} \\
& T_{3}=0.739 \mathrm{~s}, T_{4}=0.572 \mathrm{~s}, K_{S V C}=-0.8 .
\end{aligned}
$$

Using the coordinated PSSs and SVC damping controller, Mode 5 has managed to achieve adequate stability. The corresponding stability probability statistics of critical oscillation modes have increased significantly, as shown in Table VII. A comparison of detailed results is shown in Table VIII. It can be
TABLE VI

PARAMETERS OF THE PSSS AFTER COORDINATION WITH SVC DAMPING CONTROLLER

\begin{tabular}{ccccc}
\hline & PSS1 & PSS2 & PSS3 & PSS4 \\
\hline$T_{1}$ & $0.374 \mathrm{~s}$ & $0.531 \mathrm{~s}$ & $0.509 \mathrm{~s}$ & $0.314 \mathrm{~s}$ \\
$T_{2}$ & $0.549 \mathrm{~s}$ & $0.106 \mathrm{~s}$ & $0.217 \mathrm{~s}$ & $0.582 \mathrm{~s}$ \\
$K$ & 1.8 & 4.3 & 3.9 & 10 \\
\hline
\end{tabular}

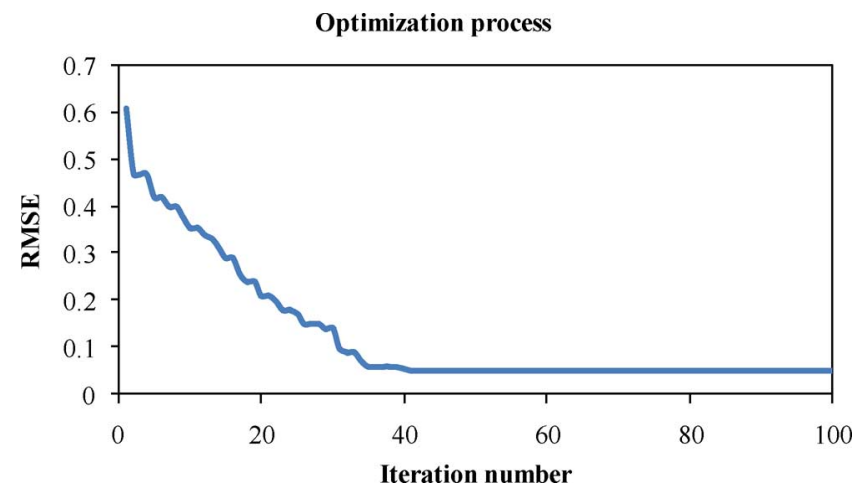

Fig. 9. Iterative RMSE trend of the model search of optimization parameters.

TABLE VII

Critical Oscillation Modes With CoOrdinated PSSS AND SVC DAMPING CONTROLLER

\begin{tabular}{ccccc}
\hline Mode & $\begin{array}{c}\text { Eigenvalues } \\
\bar{\alpha} \pm \mathrm{j} \bar{\omega}\end{array}$ & $\begin{array}{c}\text { Damping } \\
\text { ratio } \bar{\xi}\end{array}$ & $\begin{array}{c}\mathrm{P}\{\alpha<0\} \\
(\%)\end{array}$ & $\begin{array}{c}\mathrm{P}\{\xi>0.1\} \\
(\%)\end{array}$ \\
\hline 1 & $-1.5046 \pm \mathrm{j} 6.5632$ & 0.7126 & 100.00 & 99.75 \\
2 & $-1.9984 \pm \mathrm{j} 2.7294$ & 0.5574 & 100.00 & 100.00 \\
3 & $-1.8637 \pm \mathrm{j} 5.6821$ & 0.3058 & 96.35 & 95.18 \\
4 & $-1.4527 \pm \mathrm{j} 2.9618$ & 0.3673 & 97.26 & 96.47 \\
5 & $-1.5928 \pm \mathrm{j} 0.3417$ & 0.5845 & 100 & 100 \\
\hline
\end{tabular}

TABLE VIII

COMPARISON OF DETAILED Results (Original $\rightarrow$ Coordinated)

\begin{tabular}{cccc}
\hline Mode & $\begin{array}{c}\text { Damping } \\
\text { ratio } \bar{\xi}\end{array}$ & $\begin{array}{c}\mathrm{P}\{\alpha<0\} \\
(\%)\end{array}$ & \begin{tabular}{c}
$\mathrm{P}\left\{\begin{array}{c}\xi \\
(\%)\end{array}\right.$ \\
\hline 1
\end{tabular} \\
$0.37 \rightarrow 0.71$ & $63 \rightarrow 100$ & $62 \rightarrow 100$ \\
2 & $0.31 \rightarrow 0.56$ & $64 \rightarrow 100$ & $62 \rightarrow 100$ \\
3 & $0.27 \rightarrow 0.31$ & $57 \rightarrow 96$ & $54 \rightarrow 95$ \\
4 & $0.02 \rightarrow 0.37$ & $70 \rightarrow 97$ & $3 \rightarrow 96$ \\
\hline
\end{tabular}

observed that the expectation of damping ratio and the probability of all oscillation modes have improved greatly. The probabilistic stability of Mode 4 of inter-area oscillation reaches $97 \%$ and its expectation of damping ratio is increased to 0.37 and the probability of it greater than 0.1 reaches $96 \%$.

The PDF of the real parts of the inter-area oscillation Mode 4 under the four scenarios are shown in Fig. 10. All the eigenvalues plotted in the complex plane under the different scenarios are shown in Fig. 11. From Fig. 10, it is observed that 


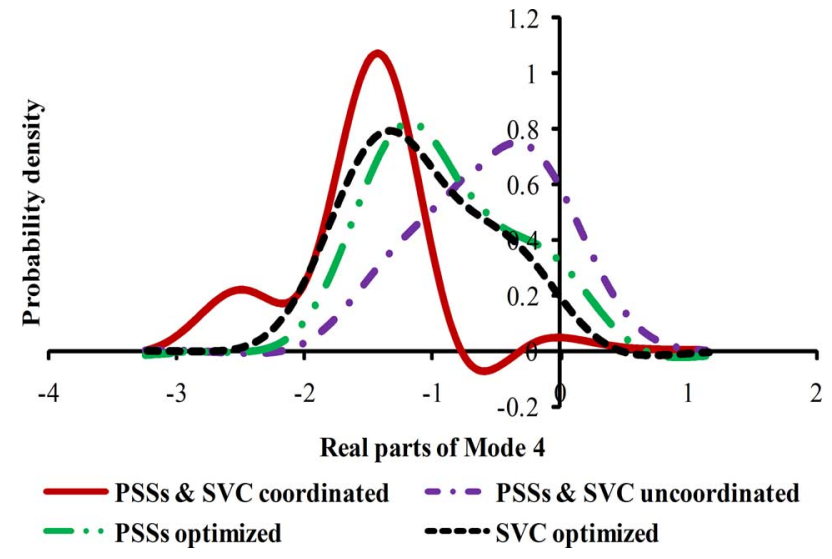

Fig. 10. Real part PDF of the Mode 4.

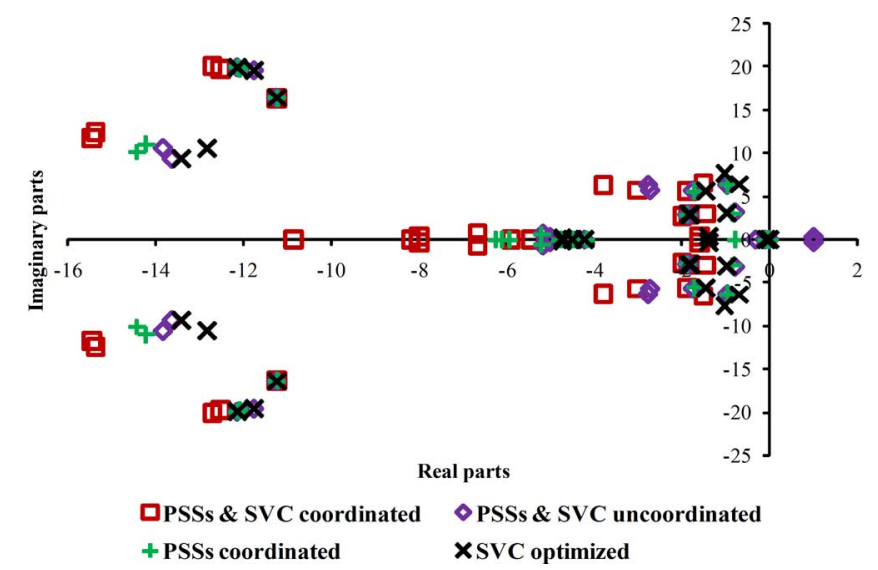

Fig. 11. Scatter diagram of concerned eigenvalues comparison of the five-machine two-area system.

the PDF curve of Mode 4 moves toward the left of the imaginary axis with the addition of SVC and it moves even further after the PSSs and the SVC damping controller are coordinated. The negative probability density value is caused because only the first five order cumulants [31] are used to simplify the calculation but ignoring higher order cumulants. This explains the appearance of truncation error. From Fig. 11, it is observed that the probabilistic eigenvalues with coordinated PSSs and SVC damping controller move further away from the imaginary axis to the left than the other three scenarios. As a result, the overall probabilistic small-signal stability is much improved with coordinated PSSs and SVC damping controller for the system with a wind farm connected.

\section{CASe Study II: Eight-Machine Three-Area System}

To investigate the applicability and scalability of the proposed method in coordinating damping controllers, a case study is undertaken and is based on the eight-machine three-area system shown in Fig. 12. The three areas are devised for clarity: G1 is the equivalent representation of Area 1; G2 - G3 belong to Area 2 and G4 - G8 belong to Area 3. The system is modified from the 36-bus test system in the "Power system analysis software package (PSASP)" [28], [29]. One of the branches

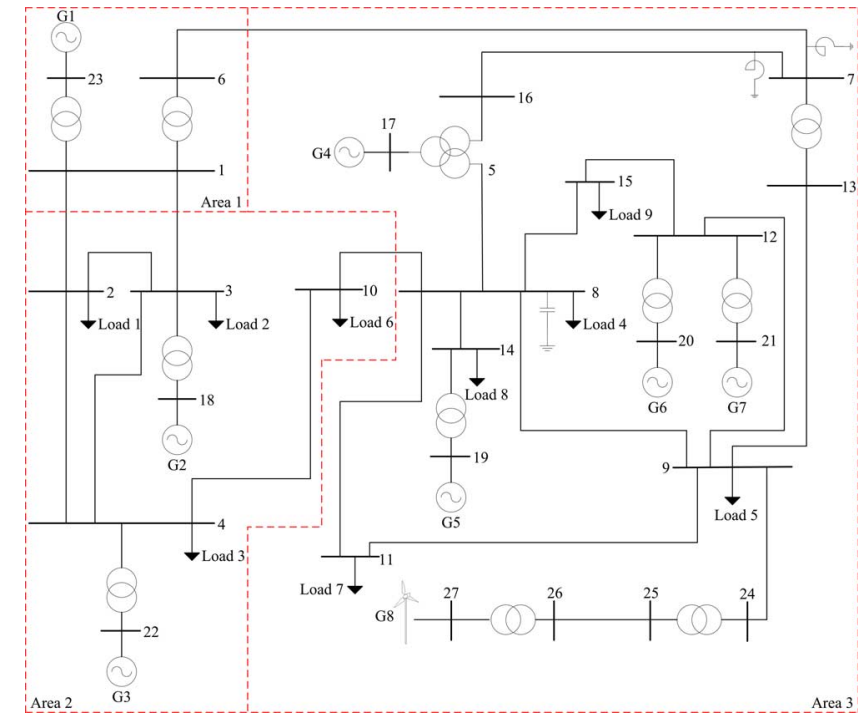

Fig. 12. Three-area system with wind farm integration.

between Bus 4 and Bus 11 is removed. The generator G2 is substituted by a wind farm G8 with a capacity of $150 \mathrm{MW}$ or 100 DFIGs with $1.5 \mathrm{MW}$ each. Details of network parameters, nodal powers and control system parameters can be referred to [28], and the modeling of the generator excitation system is provided in [29]. Normal operation values of nodal powers and PV bus voltages are regarded as their expectations. All nodal powers and PV bus voltages are assigned by cumulative probability curves obtained from standardized daily operating curves [40].

\section{A. Probabilistic Small-Signal Stability Analysis With PSSs Only}

To improve the probabilistic small-signal stability of the test system, each synchronous generator is equipped with a PSS. The Initial gains determined by the PSI corresponding to the residue index [29] and the initial time settings estimated according to the phase shift of the excitation in the system, are shown in Table IX. The statistical results of critical oscillation modes are shown in Table X. According to participation factor analysis, Mode 1, 3, 4, and 5 are local oscillation modes; Mode 2 is caused mainly by the wind farm G8; and Mode 6 and 7 are inter-area oscillation modes. Then the MFOA is implemented to optimize the parameters of PSSs. The number of swarm used is 21 .

After 100 times of iterative evolution, convergence is obtained in the 55th generation, and the corresponding RMSE is 0.0596 . The optimized parameters of PSSs are shown in Table IX.

The corresponding stability probability statistics of critical oscillation modes are presented in Table X. It is clear from the table that the optimized PSSs improve the local modes.

\section{B. Probabilistic Small-Signal Stability Analysis With SVC Damping Controllers Only}

The shape of each inter-area oscillation mode is investigated by computing the participation factors of different rotor speeds 
TABLE IX

PARAMETERS OF THE PSSS

\begin{tabular}{|c|c|c|c|c|c|c|c|}
\hline \multicolumn{8}{|c|}{ Initial parameters } \\
\hline & PSS1 & PSS2 & PSS3 & PSS4 & PSS5 & PSS6 & PSS7 \\
\hline$T_{1}(\mathrm{~S})$ & 0.865 & 0.676 & 0.723 & 0.509 & 0.317 & 0.681 & 0.760 \\
\hline$T_{2}(\mathrm{~S})$ & 0.402 & 0.329 & 0.415 & 0.284 & 0.716 & 0.473 & 0.532 \\
\hline$K$ & 3.6 & 9.8 & 1.7 & 5.1 & 5.4 & 4.4 & 8 \\
\hline \multicolumn{8}{|c|}{ Coordinated parameters } \\
\hline & PSS1 & PSS2 & PSS3 & PSS4 & PSS5 & PSS6 & PSS7 \\
\hline$T_{1}(\mathrm{~S})$ & 0.716 & 0.729 & 0.651 & 0.725 & 0.359 & 0.642 & 0.745 \\
\hline$T_{2}(\mathrm{~S})$ & 0.327 & 0.354 & 0.306 & 0.334 & 0.742 & 0.453 & 0.512 \\
\hline K & 2.6 & 8.1 & 5.2 & 5.6 & 6.3 & 5 & 7.9 \\
\hline
\end{tabular}

TABLE $X$

CRITICAL OSCILlation MODES With PSSS ONLY

\begin{tabular}{|c|c|c|c|c|}
\hline & $\begin{array}{l}\text { Eigenvalues } \\
\qquad \bar{\alpha} \pm \mathrm{j} \bar{\omega}\end{array}$ & $\begin{array}{l}\text { Damping } \\
\text { ratio } \bar{\xi}\end{array}$ & $\begin{array}{c}\mathrm{P}\{\alpha<0\} \\
(\%)\end{array}$ & $\begin{array}{c}\mathrm{P}\{\xi>0.1\} \\
(\%)\end{array}$ \\
\hline \multirow{7}{*}{$\begin{array}{l}\text { PSSs with } \\
\text { initial } \\
\text { parameters }\end{array}$} & $-0.4217 \pm \mathrm{j} 5.4091$ & 0.0676 & 70.33 & 53.26 \\
\hline & $-1.2125 \pm \mathrm{j} 2.8594$ & 0.1571 & 71.48 & 62.69 \\
\hline & $-1.0731 \pm \mathrm{j} 6.0316$ & 0.1326 & 75.23 & 61.48 \\
\hline & $-0.7264 \pm j 9.4742$ & 0.0814 & 60.57 & 56.12 \\
\hline & $-0.4913 \pm j 5.8268$ & 0.0573 & 74.96 & 14.25 \\
\hline & $-0.1149 \pm \mathrm{j} 4.2837$ & 0.0327 & 65.97 & 28.17 \\
\hline & $-0.3516 \pm \mathrm{j} 3.8127$ & 0.0916 & 49.24 & 48.29 \\
\hline \multirow{7}{*}{$\begin{array}{c}\text { PSSs } \\
\text { optimized }\end{array}$} & $-0.9825 \pm \mathrm{j} 5.4163$ & 0.1095 & 88.27 & 82.15 \\
\hline & $-1.6984 \pm j 2.8816$ & 0.2346 & 87.41 & 80.29 \\
\hline & $-1.3294 \pm \mathrm{j} 6.0981$ & 0.1827 & 86.47 & 81.26 \\
\hline & $-1.0297 \pm \mathrm{j} 9.4435$ & 0.1428 & 85.04 & 71.68 \\
\hline & $-0.8627 \pm \mathrm{j} 5.7984$ & 0.1006 & 82.36 & 65.18 \\
\hline & $-0.8193 \pm j 4.2619$ & 0.0977 & 80.24 & 53.46 \\
\hline & $-0.4682 \pm \mathrm{j} 3.7529$ & 0.1035 & 59.17 & 51.32 \\
\hline
\end{tabular}

to each mode. From Fig. 13, Mode 6 is among Areas 1, 2, and 3 , and Mode 7 is between Areas 2 and 3 .

To facilitate power transmission, two SVCs are installed on the three-area system. From the participation factors, it can be seen that Mode 6 is more correlated with Areas 1 and 3. Therefore, each SVC is allocated for the coverage of one of the two modes. To this end, one of the SVC is installed on Bus 6 (the transmission corridor between Areas 1 and 3). The current amplitude in the transmission line between Bus 6 and Bus $7 I_{6-7}$ is employed as the input signal [38], [39] of the damping controller. The other SVC is installed on Bus 10 (the transmission corridor between Areas 2 and 3). The current amplitude in the transmission line between Bus 10 and Bus $8 I_{8-10}$ is employed as the input signal [38], [39] of the damping controller.

Initial parameters of the SVC damping controller are chosen as shown in (25a) to (25d) whose gains are determined by the
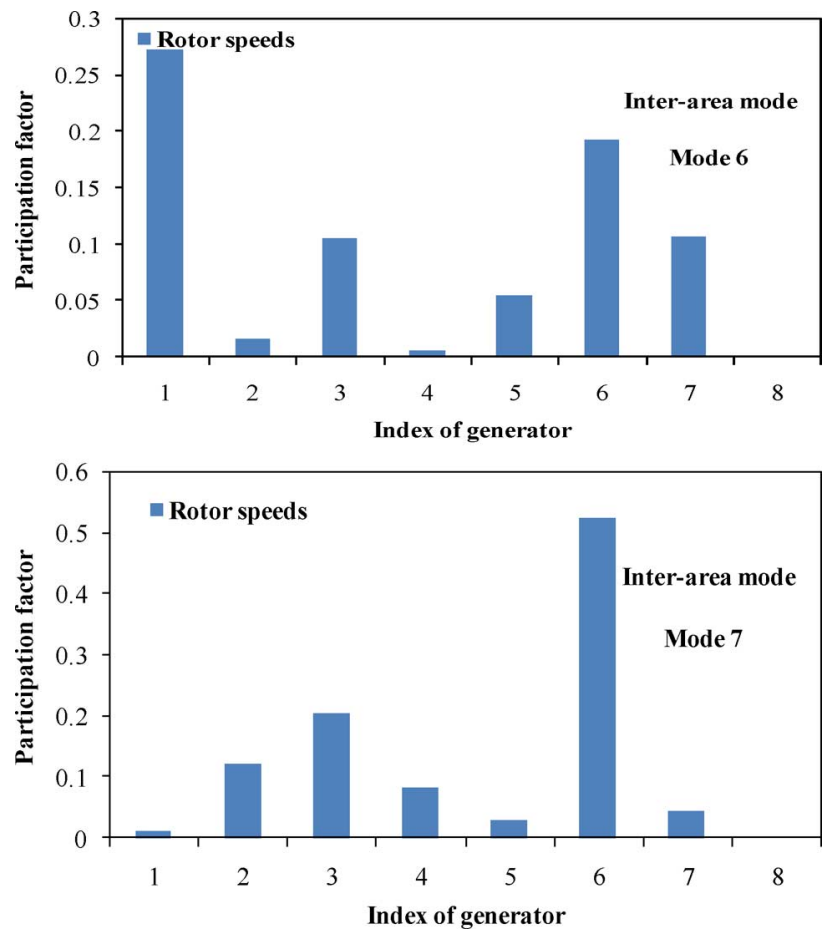

Fig. 13. Generator participation factors of dominant inter-area modes

PSI corresponding to the residue index [15], and time settings are determined by the phase-compensation method [12]. The statistical results of critical oscillation modes are shown in Table XI. Then the MFOA is implemented to optimize the parameters of the SVC damping controllers. The number of swarm used is 10 :

$$
\begin{aligned}
T_{1 S V C 1} & =0.613 \mathrm{~s}, T_{2 S V C 1}=0.205 \mathrm{~s} \\
T_{3 S V C 1} & =0.968 \mathrm{~s}, T_{4 S V C 1}=0.370 \mathrm{~s}, \\
K_{S V C 1} & =-2.6 \\
T_{1 S V C 2} & =0.501 \mathrm{~s}, T_{2 S V C 2}=0.294 \mathrm{~s} \\
T_{3 S V C 2} & =0.703 \mathrm{~s}, T_{4 S V C 2}=0.955 \mathrm{~s}, \\
K_{S V C 2} & =-3.3 .
\end{aligned}
$$

After 100 times of iterative evolution, convergence is obtained in the 32nd generation, and the corresponding RMSE is 0.0541 . The optimized parameters of the SVC damping controllers are listed in the following:

$$
\begin{aligned}
T_{1 S V C 1} & =0.917 \mathrm{~s}, T_{2 S V C 1}=0.594 \mathrm{~s} \\
T_{3 S V C 1} & =0.901 \mathrm{~s}, T_{4 S V C 1}=0.452 \mathrm{~s}, \\
K_{S V C 1} & =-1.8 \\
T_{1 S V C 2} & =0.724 \mathrm{~s}, T_{2 S V C 2}=0.281 \mathrm{~s} \\
T_{3 S V C 2} & =0.624 \mathrm{~s}, T_{4 S V C 2}=0.860 \mathrm{~s}, \\
K_{S V C 2} & =-0.9 .
\end{aligned}
$$

The corresponding stability probability statistics of critical oscillation modes are presented in Table XI. It is clear that the optimized SVC damping controllers improve the inter-area modes (Mode 6 and 7). 
TABLE XI

CRitical Oscillation Modes With SVC Damping CONTROLlers ONLY

\begin{tabular}{|c|c|c|c|c|}
\hline & $\begin{array}{l}\text { Eigenvalues } \\
\qquad \bar{\alpha} \pm \mathbf{j} \bar{\omega}\end{array}$ & $\begin{array}{l}\text { Damping } \\
\text { ratio } \bar{\xi}\end{array}$ & $\begin{array}{c}\mathrm{P}\{\alpha<0\} \\
(\%)\end{array}$ & $\begin{array}{c}\mathrm{P}\{\xi>0.1\} \\
(\%)\end{array}$ \\
\hline \multirow{7}{*}{$\begin{array}{l}\text { SVC with } \\
\text { initial } \\
\text { parameters }\end{array}$} & $-0.3912 \pm \mathrm{j} 5.3929$ & 0.0497 & 55.27 & 42.61 \\
\hline & $-1.0391 \pm \mathbf{j} 2.8637$ & 0.1059 & 62.14 & 50.23 \\
\hline & $-0.9026 \pm \mathrm{j} 6.0896$ & 0.1182 & 63.87 & 54.29 \\
\hline & $-0.7093 \pm \mathrm{j} 9.4816$ & 0.0615 & 55.04 & 43.92 \\
\hline & $-0.3158 \pm \mathrm{j} 5.7623$ & 0.0395 & 60.18 & 7.4 \\
\hline & $-0.6028 \pm \mathbf{j} 4.2717$ & 0.0814 & 75.39 & 46.13 \\
\hline & $-0.6913 \pm \mathrm{j} 3.8267$ & 0.1343 & 70.94 & 61.26 \\
\hline \multirow{7}{*}{$\begin{array}{c}\text { SVC } \\
\text { optimized }\end{array}$} & $-0.3906 \pm \mathbf{j} 5.3921$ & 0.0496 & 55.23 & 42.60 \\
\hline & $-1.0342 \pm \mathrm{j} 2.8636$ & 0.1053 & 62.10 & 50.22 \\
\hline & $-0.9027 \pm \mathrm{j} 6.0896$ & 0.1182 & 63.87 & 54.29 \\
\hline & $-0.7106 \pm \mathbf{j} 9.4817$ & 0.0619 & 59.15 & 44.11 \\
\hline & $-0.3152 \pm \mathrm{j} 5.7624$ & 0.0394 & 60.16 & 7.4 \\
\hline & $-1.1694 \pm \mathrm{j} 4.2033$ & 0.1258 & 86.34 & 72.17 \\
\hline & $-1.0063 \pm \mathrm{j} 3.8412$ & 0.1672 & 87.92 & 81.12 \\
\hline
\end{tabular}

TABLE XII

Critical Oscillation Modes With Uncoordinated PSSS AND SVC CONTROLLERS

\begin{tabular}{|c|c|c|c|c|}
\hline Mode & $\begin{array}{l}\text { Eigenvalues } \\
\qquad \bar{\alpha} \pm \mathbf{j} \bar{\omega}\end{array}$ & $\begin{array}{l}\text { Damping } \\
\text { ratio } \bar{\xi}\end{array}$ & $\begin{array}{c}\mathrm{P}\{\alpha<0\} \\
(\%)\end{array}$ & $\begin{array}{c}\mathrm{P}\{\xi>0.1\} \\
(\%)\end{array}$ \\
\hline 1 & $-0.9984 \pm \mathbf{j} 5.3736$ & 0.1097 & 89.06 & 82.32 \\
\hline 2 & $-1.6213 \pm \mathrm{j} 2.8683$ & 0.2275 & 83.11 & 76.53 \\
\hline 3 & $-1.3307 \pm \mathrm{j} 6.0831$ & 0.1899 & 88.35 & 82.62 \\
\hline 4 & $-1.0133 \pm \mathrm{j} 9.4713$ & 0.1343 & 84.54 & 70.30 \\
\hline 5 & $-0.8089 \pm \mathrm{j} 5.7821$ & 0.0866 & 76.53 & 61.07 \\
\hline 6 & $-0.1098 \pm \mathrm{j} 4.1188$ & 0.0273 & 61.95 & 24.40 \\
\hline 7 & $-0.3242 \pm \mathrm{j} 3.8072$ & 0.0871 & 47.47 & 45.71 \\
\hline 8 & $0.1891 \pm \mathrm{j} 0.1753$ & -0.7333 & 5.32 & 0.00 \\
\hline
\end{tabular}

\section{Probabilistic Small-Signal Stability Analysis With Uncoordinated PSSs and SVC Damping Controllers}

PSSs and SVCs are installed to improve the probabilistic stability of the test system. PSSs parameters are the same as those in Table IX of Section VI-A. SVCs parameters are the same as the optimized parameters in (26) of Section VI-B.

The statistical results of critical oscillation modes are shown in Table XII. Comparing Table XII with Table XI, the damping ratio expectation of the inter-area modes (Mode 6 and 7) decreases dramatically. Furthermore, there is a new oscillation mode (Mode 8), and the expectation of its damping ratio is -0.7333 . All these non-ideal oscillation modes above are
TABLE XIII

PARAMETERS OF THE PSSS AFTER COORDINATION

\begin{tabular}{cccccccc}
\hline & PSS1 & PSS2 & PSS3 & PSS4 & PSS5 & PSS6 & PSS7 \\
\hline$T_{1}(\mathrm{~S})$ & 0.827 & 0.714 & 0.694 & 0.618 & 0.329 & 0.872 & 0.774 \\
$T_{2}(\mathrm{~S})$ & 0.518 & 0.312 & 0.370 & 0.431 & 0.682 & 0.549 & 0.597 \\
$K$ & 4 & 9.5 & 4.3 & 6.7 & 2.8 & 6.1 & 8.9 \\
\hline
\end{tabular}

Optimization process

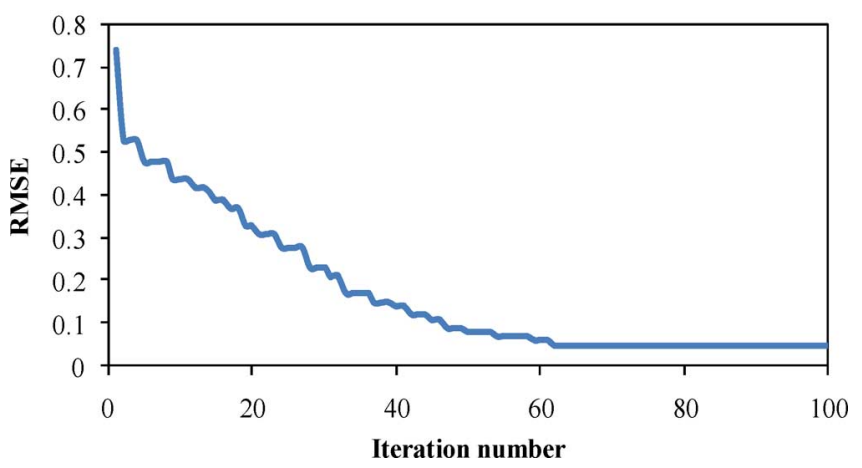

Fig. 14. Iterative RMSE trend of the model search of optimization parameters.

TABLE XIV

CRITICAL OSCILlation MODES With COORDINATED PSSS AND SVC CONTROLLERS

\begin{tabular}{ccccc}
\hline Mode & $\begin{array}{c}\text { Eigenvalues } \\
\bar{\alpha} \pm \mathrm{j} \bar{\omega}\end{array}$ & $\begin{array}{c}\text { Damping } \\
\text { ratio } \bar{\xi}\end{array}$ & $\begin{array}{c}\mathrm{P}\{\alpha<0\} \\
(\%)\end{array}$ & $\begin{array}{c}\mathrm{P}\{\xi>0.1\} \\
(\%)\end{array}$ \\
\hline 1 & $-1.1910 \pm \mathrm{j} 5.3924$ & 0.1790 & 100.00 & 99.34 \\
2 & $-2.0697 \pm \mathrm{j} 2.8685$ & 0.2872 & 100.00 & 100.00 \\
3 & $-2.0053 \pm \mathrm{j} 6.0933$ & 0.2428 & 100.00 & 100.00 \\
4 & $-1.5024 \pm \mathrm{j} 9.4526$ & 0.1769 & 100.00 & 100.00 \\
5 & $-1.0619 \pm \mathrm{j} 5.8171$ & 0.1497 & 100.00 & 100.00 \\
6 & $-1.5217 \pm \mathrm{j} 4.2692$ & 0.1926 & 98.02 & 97.29 \\
7 & $-1.1495 \pm \mathrm{j} 3.8825$ & 0.1803 & 100.00 & 96.84 \\
8 & $-1.6116 \pm \mathrm{j} 0.1507$ & 0.3690 & 100.00 & 100.00 \\
\hline
\end{tabular}

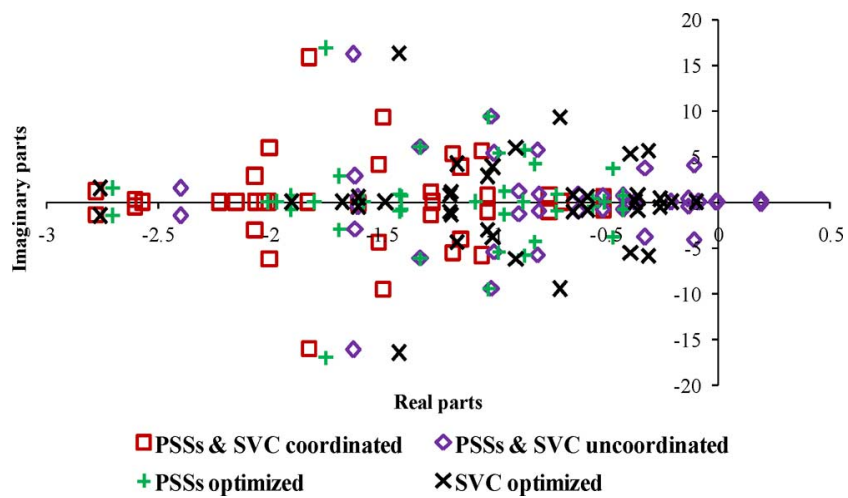

Fig. 15. Scatter diagram of concerned eigenvalues comparison of the eightmachine three-area system.

caused by the uncoordinated design of PSSs and SVC damping controllers. 


\section{Probabilistic Small-Signal Stability Analysis With Coordinated PSSs and SVC Damping Controllers}

In order to coordinate the PSSs and SVC damping controllers, the MFOA is implemented. The number of swarm used is 31 .

Fig. 14 gives the convergent characteristics of the MFOA. It can be seen from the curve that convergent is obtained in the 62nd generation, and the corresponding RMSE is 0.0503 . The final values of optimized parameters of PSSs are shown in Table XIII and the parameters of SVC damping controllers are listed respectively in the following:

$$
\begin{aligned}
T_{1 S V C 1} & =0.849 \mathrm{~s}, T_{2 S V C 1}=0.602 \mathrm{~s} \\
T_{3 S V C 1} & =0.965 \mathrm{~s}, T_{4 S V C 1}=0.473 \mathrm{~s} \\
K_{S V C 1} & =-1.0 \\
T_{1 S V C 2} & =0.571 \mathrm{~s}, T_{2 S V C 2}=0.304 \mathrm{~s} \\
T_{3 S V C 2} & =0.594 \mathrm{~s}, T_{4 S V C 2}=0.977 \mathrm{~s} \\
K_{S V C 2} & =-0.6 .
\end{aligned}
$$

The corresponding stability probability statistics of critical oscillation modes are presented in Table XIV. It is clear that the optimized PSSs and SVC damping controllers effectively improve the overall probabilistic small-signal stability of the power system with a wind farm connected.

The eigenvalues under the four scenarios are presented in Fig. 15. It is observed that the overall probabilistic small-signal stability is much improved with the coordinated PSSs and SVC damping controllers for the system with wind farm integration.

\section{CONCLUSIONS}

The combined use of MFOA and probabilistic theory to search for the best combination of PSSs and SVC damping controller parameters has been presented in the paper. The aim is to improve the probabilistic small-signal stability of the power system with synchronous machines and DFIG-based wind power generation. A wide range of operating conditions have been considered including the random fluctuations of the wind farm output and the synchronous generators output, stochastic characteristics of loads and nodal voltages. The simulation results based on the two test systems have demonstrated that the stochastic output of the wind farm deteriorates the probabilistic small-signal stability of power systems. When a wind farm is integrated into a power system, the distribution of its system eigenvalues covers a wider range. This makes it more difficult to improve the probabilistic small-signal stability of the power system with PSSs only, especially to the inter-area oscillation. The power system with uncoordinated PSSs and SVC damping controller may produce negative interaction with each other. Coordinated and optimized PSSs and SVC damping controller based on the proposed method can improve the whole probabilistic small-signal stability of power systems with wind farm integration.

\section{REFERENCES}

[1] S. Q. Bu, W. Du, H. F. Wang, Z. Chen, L. Y. Xiao, and H. F. Li, "Probabilistic analysis of small-signal stability of large-scale power systems as affected by penetration of wind generation," IEEE Trans. Power Syst., vol. 27, no. 2, pp. 762-770, May 2012.
[2] M. Kiaee, A. Cruden, D. Infield, and P. Chladek, "Utilisation of alkaline electrolysers to improve power system frequency stability with a high penetration of wind power," IET Renew. Power Gener., vol. 8, no. 5, pp. 529-536, Jul. 2014.

[3] F. M. Hughes, O. Anaya-Lara, N. Jenkins, and G. Strbac, "Control of DFIG-based wind generation for power network support," IEEE Trans. Power Syst., vol. 20, no. 4, pp. 1958-1966, Nov. 2005.

[4] H. Yu, C. Y. Chung, K. P. Wong, and J. H. Zhang, "A change constrained transmission network expansion planning method with consideration of load and wind farm uncertainties," IEEE Trans. Power Syst., vol. 24, no. 3, pp. 1568-1576, Aug. 2009.

[5] J. L. Rueda and D. G. Colome, "Probabilistic performance indexes for small signal stability enhancement in weak wind-hydro-thermal power systems," IET Gener. Transm. Distrib., vol. 3, no. 8, pp. 733-747, Aug. 2009.

[6] H. Yue, G. Y. Li, and M. Zhou, "A probabilistic approach to small signal stability analysis of power systems with correlated wind sources," J. Electr. Eng. Technol., vol. 8, no. 6, pp. 1605-1614, Aug. 2013.

[7] S. Q. Bu, W. Du, and H. F. Wang, "Probabilistic analysis of smallsignal rotor angle/voltage stability of large-scale AC/DC power systems as affected by grid-connected offshore wind generation," IEEE Trans. Power Syst., vol. 28, no. 4, pp. 3712-3719, Nov. 2013.

[8] X. Y. Bian, X. X. Huang, K. C. Wang, K. L. Lo, Y. Fu, and S. H. Xuan, "Improvement on probabilistic small-signal stability of power system with large-scale wind farm integration," Int. J. Electr. Power Energy Syst., vol. 61, pp. 482-488, Oct. 2014.

[9] Y. C. Chang, "Multi-objective optimal SVC installation for power system loading margin improvement," IEEE Trans. Power Syst., vol. 27, no. 2, pp. 984-992, May 2012.

[10] T. Ahmed, O. Noro, and M. Nakaoka, "Terminal voltage regulation characteristics by static VAR compensator for a three-phase self-excited induction generator," IEEE Trans. Ind. Appl., vol. 40, no. 4, pp. 978-988, Jul. 2004.

[11] J. C. Deng, C. Li, and X. P. Zhang, "Coordinated design of multiple robust FACTS damping controllers: A BMI-based sequential approach with multi-model systems," IEEE Trans. Power Syst., to be published.

[12] W. Yao, L. Jiang, J. Y. Wen, Q. H. Wu, and S. J. Cheng, "Wide-area damping controller of FACTS devices for inter-area oscillations considering communication time delays," IEEE Trans. Power Syst., vol. 29, no. 1, pp. 318-329, Jan. 2014.

[13] L. J. Cai and I. Erlich, "Simultaneous coordinated tuning of PSS and FACTS damping controllers in large power systems," IEEE Trans. Power Syst., vol. 20, no. 1, pp. 294-300, Feb. 2005.

[14] M. A. Abido and Y. L. Abdel-Magid, "Coordinated design of a PSS and an SVC-based controller to enhance power system stability," Int. J. Electr. Power Energy Syst., vol. 25, no. 9, pp. 695-704, Nov. 2003.

[15] X. Y. Bian, C. T. Tse, J. F. Zhang, and K. W. Wang, "Coordinated design of probabilistic PSS and SVC damping controllers," Int. J. Electr. Power Energy Syst., vol. 33, pp. 445-452, Mar. 2011.

[16] A. L. B. D. Bomfim, G. N. Taranto, and D. M. Falcão, "Simultaneous tuning of power system damping controllers using genetic algorithms," IEEE Trans. Power Syst., vol. 15, no. 1, pp. 163-169, Feb. 2000.

[17] L. H. Hassan, M. Moghavvemi, H. A. F. Almurib, and K. M. Muttaqi, "A coordinated design of PSSs and UPFC-based stabilizer using genetic algorithm," IEEE Trans. Ind. Appl., vol. 50, no. 5, pp. 2957-2966, Sep. 2014.

[18] I. Ngamroo, "Simultaneous optimization of SMES coil size and control parameters for robust power system stabilization," IEEE Trans. Appl. Supercond., vol. 21, no. 3, pp. 1358-1361, Jun. 2011.

[19] W. T. Pan, "A new fruit fly optimization algorithm: Taking the financial distress model as an example," Knowl. Based Syst., vol. 26, pp. 69-74, Feb. 2012

[20] W. T. Pan, Fruit Fly Optimization Algorithm. Taipei, Taiwan: Tsang Hai Book Publishing Company, 2011, pp. 10-12.

[21] C. T. Tse and C. Y. Chung, "An Electric Power Network Modeling Method," U.S. No. US6, Nov. 3, 2001.

[22] H. D. Dai, G. R. Zhao, J. H. Lu, and S. W. Dai, "Comment and improvement on 'A new Fruit Fly Optimization Algorithm: Taking the financial distress model as an example'," Knowl. Based Syst., vol. 59, pp. 159-160, Mar. 2014.

[23] W. T. Pan, "Using modified fruit fly optimization algorithm to perform the function test and case studies," Connect. Sci., vol. 25, no. 2-3, pp. 151-160, Jun. 2013. 
[24] C. Q. Li, S. P. Xu, W. Li, and L. Y. Hu, "A novel modified fly optimization algorithm for designing the self-tuning proportional integral derivative controller," J. Converg. Inf. Technol., vol. 7, no. 16, pp. 69-77, Sep. 2012.

[25] E. V. Larsen and D. A. Swann, "Applying power system stabilizers," IEEE Trans. Power App. Syst., vol. PAS-100, no. 6, pp. 3017-3046, Jun. 1981

[26] S. E. M. De Oliveira, "Synchronizing and damping torque coefficients and power system steady-state stability as affected by static VAR compensators," IEEE Trans. Power Syst., vol. 9, no. 1, pp. 109-119, Feb. 1994.

[27] C. Y. Chung, C. T. Tse, K. W. Wang, A. K. David, and C. W. Yu, "Synthesis of sensitivity coefficients for controller parameters of static VAR compensator," IEE Proc.-Gener. Transm. Distrib., vol. 147, no. 4, pp. 223-230, Jul. 2000.

[28] X. Y. Bian, "Probabilistic robust damping controller designs for FACTS devices and PSS," Ph.D. dissertation, Hong Kong Polytechnic Univ., Hong Kong, China, 2006.

[29] C. Y. Chung, K. W. Wang, C. T. Tse, X. Y. Bian, and A. K. David, "Probabilistic eigenvalue sensitivity analysis and PSS design in multi-machine systems," IEEE Trans. Power Syst., vol. 18, no. 4, pp. 1439-1445, Nov. 2003.

[30] X. F. Wang and J. McDonald, Modern Power System Planning. New York, NY, USA: McGraw-Hill, 1994, vol. I, p. 465.

[31] K. W. Wang, C. Y. Chung, C. T. Tse, and K. M. Tsang, "Improved probabilistic method for power system dynamic stability studies," IET Gener. Transm. Distrib., vol. 147, no. 1, pp. 37-43, Jan. 2000.

[32] M. G. Kendall and A. Stuart, The Advanced Theory of Statistics. New York, NY, USA: Hafner, 1977, vol. I, pp. 84-88.

[33] P. Kundur, Power System Stability and Control. New York, NY, USA: McGraw-Hill, 1994, pp. 130-157.

[34] F. Mei and B. C. Pal, "Model analysis of grid-connected doubly fed induction generators," IEEE Trans. Energy Convers., vol. 22, no. 3, pp. 728-736, Sep. 2007.

[35] B. C. Pal and F. Mei, "Modelling adequacy of the doubly fed induction generator for small-signal stability studies in power systems," IET Renew. Power Gener., vol. 2, no. 3, pp. 181-190, Sep. 2008.

[36] F. Wu, X. P. Zhang, K. Godfrey, and P. Ju, "Small signal stability analysis and optimal control of a wind turbine with doubly fed induction generator," IET Gener. Transm. Distrib., vol. 1, no. 5, pp. 751-760, Jul. 2007.

[37] M. Noroozian, M. Ghandhari, G. Andersson, J. Gronquist, and I. Hiskens, "A robust control strategy for shunt and series reactive compensators to damp electromechanical oscillations," IEEE Trans. Power Del., vol. 16, no. 4, pp. 812-817, Oct. 2001.

[38] X. Y. Bian, C. Y. Chung, K. W. Wang, and C. T. Tse, "Choice of SVC location/signal and its controller design by probabilistic method," Electr. Power Syst. Res., vol. 71, no. 1, pp. 35-40, Sep. 2004.

[39] C. Y. Chung, C. T. Tse, K. W. Wang, A. K. David, and C. W. Yu, "Synthesis of sensitivity coefficients for controller parameters of static VAr compensator," IET Gener. Transm. Distrib., vol. 147, no. 4, pp. 223-230, Jul. 2000.

[40] K. W. Wang, C. T. Tse, and K. M. Tsang, "Algorithm for power system dynamic stability studies taking account the variation of load power," Electr. Power Syst. Res., vol. 46, no. 3, pp. 221-227, Sep. 1998.

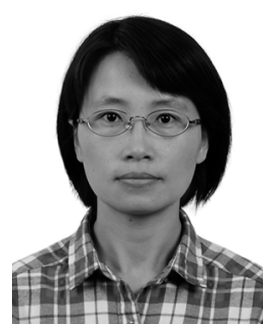

X. Y. Bian ( $\left.\mathrm{S}^{\prime} 05-\mathrm{M}^{\prime} 14\right)$ received the Ph.D. degree from the Hong Kong Polytechnic University, Hong Kong, China, in 2006.

Now she works in Shanghai University of Electric Power, China, as a Professor. Her employment experience included that the Shuangliao Power Plant and the Electrical Engineering Department, The Hong Kong Polytechnic University. Her special fields of interest include power system stability and control, renewable energy integration, power system planning and operation, and control of FACTS

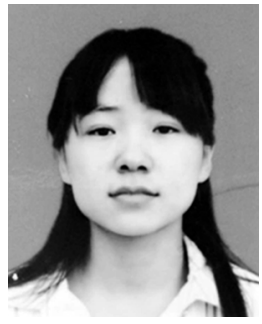

Yan Geng received the B.E. degree from the Electric Engineering College, Northeast University of Electric Power, China, in 2012. Currently, she is pursuing the M.S. degree in Electric Engineering College at Shanghai University of Electric Power, China.

Her special fields of interest include wind generation integration, power system stability, and control.

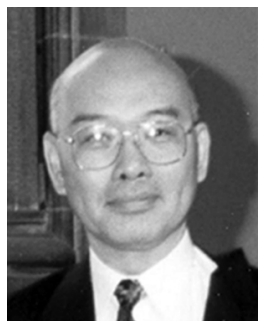

Kwok L. Lo received the M.Sc. and Ph.D. degrees from the University of Manchester Institute of Science and Technology, U.K.

Currently he is Research Professor of Power Systems and Head of the Power Systems Research Group at the University of Strathclyde, U.K. His special fields of interest include power systems analysis, planning, operation, monitoring, and control, including energy market liberalization issues.

Prof Lo is a Fellow of IET and a Fellow of the Royal Society of Edinburgh.

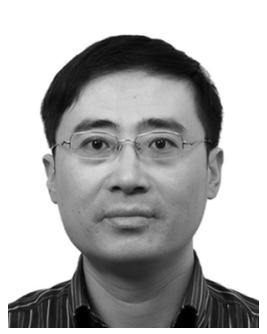

Yang Fu received the Ph.D. degree from Shanghai University, Shanghai, China, in 2005.

Currently he is Professor and the head of Electrical Engineering College at Shanghai University of Electric Power. His special fields of interest include power system planning, operation and control, and renewable energy.

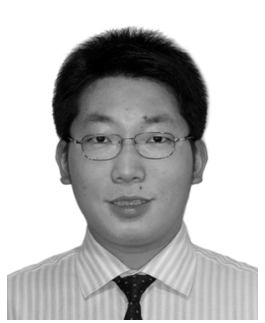

Q. B. Zhou received the B.Sc. and M.Sc. degrees in electrical engineering from Shanghai Jiao Tong University and the Ph.D degree from the HongKong Polytechnic University.

Now he works at Shanghai Lightning Protection Center. His research interests include wind power, power system overvoltage, and electromagnetic compatibility.

devices. 